\title{
Simulation and Modeling of Port-industry-city System Based on Complex Adaptive System
}

\author{
Jiang Liupeng, a , Zhang Yan ${ }^{1, b}$, Feng Xuejun ${ }^{1, c}$, Yang Yilin ${ }^{1, d}$ \\ ${ }^{1}$ Institute of Port, Coastal and Offshore Engineering, Hohai University, Nanjing, 210098, China \\ ajiangliupeng@gmail.com, b2007_zy@hhu.edu.cn, ‘fxj@hhu.edu.cn, d2275100871@qq.com
}

Keywords: Port-industry-city complex system, Spatial evolution, Complex adaptive system, Port agent, Industry agent

\begin{abstract}
In the economic development of port-surrounding regions, there exists a strong correlation among port, city and industry. They depend on each other and influence each other. To study regional economy in port, we must take port-industry-city complex system (PICCS) as the research object. By means of the "bottom-up" model strategy of regional spatial evolution simulation, this paper abstracted the port Agent and industry Agent, and put them into the transport market, analyzed the interactions and changes of each Agents in the Containers. To build a PICCS spatial evolution model based on Complex Adaptive System (CAS), and summarized the PICCS spatial evolution patterns. With the above theoretical analysis, this paper used Java software to build the simulation platform of PICCS spatial system. Simulated a visualization PICCS spatial evolution process in a given area $(30 * 30)$, and verified the feasibility of this model.
\end{abstract}

\section{Introduction}

At present, the development of Chinese port cites is in a period of acceleration. Its development background is far more complex than the climax period of urbanization in western developed countries and most developing countries. Ports, industries and cities scramble for social resources (including land, labor, industrial and environment) extremely intensely. Under the condition of "resource saving, environment friendly", it's necessary to strengthen the research on the mechanism and the simulation of PICCS spatial evolution. It can reasonably formulate the development scale of port city to avoid the waste of land and shoreline. At the same time, a reasonable expansion rate of port cities can be formulated to avoid excessive expansion of city scale, optimize the scale and structure of port and city, and improve the economic and social benefits of port and city, so as to improve the comprehensive competitiveness of the port city.

\section{Research Summary and Evaluation}

McCallas,Stephanie E discussed the multiple impact of the port's economic activities on the city and the relationship between the port and the city, but their research is limited to the qualitative analysis such as "the interaction between port and city", "invigorating the city through the port" [1-2]. Wang takes the Pearl River Delta as the research object, and put forward the general evolution process of container port [3]. Song pointed out the globalization development and the shipping alliance, the large-size and diversification of ship, intensified competition between ports are the main force to promote the port competition [4]. Notteboom put forward the development model of the port area, and further expounded the process and power of port-city linkage development [5]. Chen and Feng point out that there is a strong correlation among port, city and industry. On this basis, it forms a complex relationship among port cluster, city cluster and industry cluster. And this kind of "three cluster" relationship also constitutes an important part of regional integration [6-9]. $\mathrm{Zi}$ puts forward the impact of port-industry cluster on regional economic development, they think that the development of port-industry cluster can achieve the scale of the port-industry and have a driving effect on regional economy [10]. Yang establishes the development 
evolution model of port city and empirically analyzes the evolution of relationship between port and city. They think that the interactive development between port and city needs theory evidence [11].

In the view of the existing research's theories and methods, the research on the spatial evolution mechanism of port, industry and city is mostly fragmented. The elements have not been integrated into the unified system. They neglect the symbiotic relationship among the three. Meanwhile, the existing researches on the spatial evolution mechanism of port-industry-city system are based on the traditional economics. They assume that the spatial factor is homogeneous, so spatial factor has never been included in their evolution model. It's difficult for them to overcome their own shortcomings when they interpret the problem of spatial evolution among port, industry and city.

\section{Modeling Study}

In the PICCS spatial evolution model, the evolution space is assumed to be a two dimensional grid $M \times N$. The main body of simulation includes industrial Agent and port Agent. These two kinds of main body trade in the transportation service market. The port Agent is the provider of transportation service, and provides the homogeneous transportation service through the berth. The port industry Agent demands for transport service. It achieves the distribution of raw materials and industrial products by purchasing transportation service.

Supply Agent represents port Agent in PICCS spatial evolution model. It provides no differentiated transport products and service. The collection of supply Agent is port cluster. Port Agent has 12 properties. The collection of its properties is:

$$
P_{\text {port }}=\left[P_{i}, l_{i}, t_{i}, q_{i}, q_{\max }, \mu, c_{l}, c_{f}, c_{s}, p_{1}, c_{p}, \pi_{p}\right]
$$

$P_{\text {port }}$ in formula (1) represents the collection of port Agent's properties. $P_{i}$ is port coordinate. $l_{i}$ is the generation of port berth's development. $t_{i}$ is transfer coefficient of port. $q_{i}$ is completed port throughput. $q_{\max }$ is maximum port throughput. $\mu$ is the saturation degree of port, and $\mu=q_{i} / q_{\max } . c_{l}$ is the cost of port generation upgrading. $c_{f}$ is the fixed cost of port construction. $c_{s}$ is the cost of port throughput. $p_{1}$ is the unit transport price of port. $c_{p}$ is the unit production cost of port. $\pi_{c}$ is the production and operation profit during current cycle of port.

\section{The Property and Action of Transportation Demand Agent}

Demand Agent represents transporting products and servicing enterprises which have demand in PICCS, namely port industry Agent. Considering the demand of research, the port industry Agent has been taken a relatively simple process. The property's collection of industry Agent is:

$$
P_{\text {industry }}=\left[P_{\text {industry }}^{i}, d_{i}, I d_{\text {port }}, d_{i j}\right]
$$

In formula (3), $P_{\text {industry }}^{i}$ is the coordinate of industry Agent; $d_{i}$ is the freight volume of current cyclical demand in industry Agent; $I d_{p o r t}$ is choosing supply port; $d_{i j}$ is the freight volume when the $i$ th industry Agent chooses to pass through port $j$.

The freight volume of current cyclical demand $d_{i}$ : It is the total service volume of container transportation which is needed by port industry Agent in a running cycle. When it comes to port industry Agent, the freight volume of current cyclical demand is determined by the demand of raw materials. According to the previous hypotheses, the raw materials that port industry Agent needs for production are provided by external area, and port industry Agent purchases raw materials through port Agent. And assume that the freight volume of raw material that port industry $i$ needs is $q_{s}$, there is a linear relationship between $q_{s}$ and $d_{i}$. So the freight volume of port industry $i$ is: 
In formula (4), $d_{i}$ is the requirement of container transportation in the port industry Agent. $q_{s}$ is the freight volume of raw material that port industry $i$ needs. $\kappa_{i}$ is the port freight coefficient of raw material. Different types of raw materials has different coefficient for port freight. $q_{i}$ is the production of manufactured goods in the port industry Agent. $a, b$ are linear coefficient.

In transportation market, the port industry is the demand side. The port industry Agent completes the transportation service of raw material through port Agent. The action of port industry Agent is:

$$
F_{\text {industry }}=\left\{f_{\text {buy }}\right\}
$$

In formula (5), $f_{b u y}$ is purchasing transportation service, when the port industry Agent chooses container transportation port, it follows the maximum utility principle that transportation cost is small, the transportation efficiency is high, and so on. In each cycle, Port industry Agent's selection to port Agent generate a probability that whether to consider changing the selected port. The probability is proportional to the utility of port industry, in order to determine the final relocation place. At the time of $t$, with regard to port industry Agent $i_{\text {in }}$ the hinterland of intersection, the utility function of port $j$ is:

$$
U_{i, j}=\alpha U_{\text {distance }}+\beta U_{\text {logist }}+\chi U_{\text {price }}+\mu_{i j}
$$

In formula (6), $U_{i, j}$ is port industry Agent $i$ 's utility function to port. $U_{\text {distance }}$ is the distance function of port industry Agent $i$ and port $j . U_{\text {logist }}$ is the transportation cost of $j$ after standardization. $U_{\text {price }}$ is the unit transportation price of $j$ after standardization. $\alpha, \beta, \chi$ is the preference weight of different port industry to index, and $\alpha+\beta+\chi=1$. $\mu_{i j}$ is random disturbance term of utility equation. Different types of port industry Agent have different weights (preferences) for the distance function, the cost of logistics, and freight price of port.

$$
U_{\text {distance }}=d_{i j}=\sqrt{\left(x_{i}-x_{j}\right)^{2}+\left(y_{i}-y_{j}\right)^{2}}
$$

In formula (7), $d_{i j}$ is the distance from port industry Agent $i$ to port Agent $j$.

$$
U_{\text {logist }}=\sum_{i} \sum_{j} C_{i j}
$$

In formula (8), $C_{i, j}$ is the unit logistics cost from port industry Agent $i$ to port Agent $j$.

In the PICCS spatial evolution model, the port industry Agent randomly selects a number of suitable port Agents within their own space, and calculates respective location effect. When the selection radius of port industry is $r$, the number of randomly selected port Agent is $N$, its collection of all selected alternative ports is:

$$
A=\left(\text { Agent }_{1}, \text { Agent }_{2}, \cdots, \text { Agent }_{N}\right)
$$

In formula (9), $A$ is all alternative ports' collection of port industry. Agent $_{1}$, Agent $_{2}, \cdots$, Agent $_{N}$ are alternative ports. Port industry first selects the most utility $\left(U_{i j}\right)$ port Agent $_{x}$ in alternative ports' collection $A$, that is to say:

$$
\begin{aligned}
& U_{x}=\max \left(U_{1}, U_{2}, \cdots U_{N}\right) \\
& I d=P_{x}=\left(x_{x}, y_{x}\right)
\end{aligned}
$$

At the time of $t$, the probability that port Agent $x$ is selected as a transportation port by port 
industry Agent $i$ is:

$$
P_{i x}=\frac{\exp \left(\mu^{\prime} U_{x}\right)}{\exp \left(\mu^{\prime} U_{x}\right)+\exp \left(\mu^{\prime} U_{i}\right)}
$$

In formula (12), $U_{x}$ is the utility function of alternative port Agent $x . U_{i}$ is the utility function of current port Agent . $^{\prime} \mu^{\prime}$ is discrete parameter.

\section{Example Simulation}

In this paper, the PICCS spatial evolution simulation program is compiled based on the Java platform. Its start control and part of the parameter setting's control are shown in the following Fig. 1. A black small square represents a grid. The black small square with aqua green hue represents an industry Agent. The black small square with rose red hue represents that there are two or more industry Agents in this grid. The black small square with pink hue represents that there is a port in this grid. The black small square with yellow hue represents that there are two or more ports in this grid.

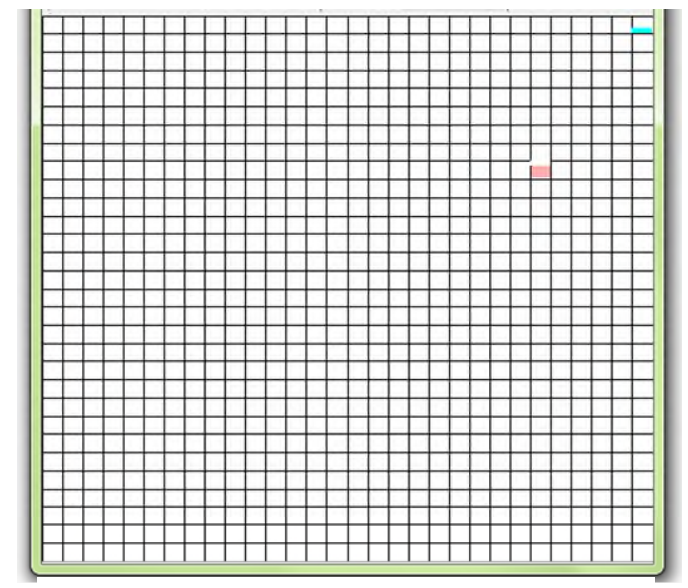

a. The initial state of PICCS spatial evolution

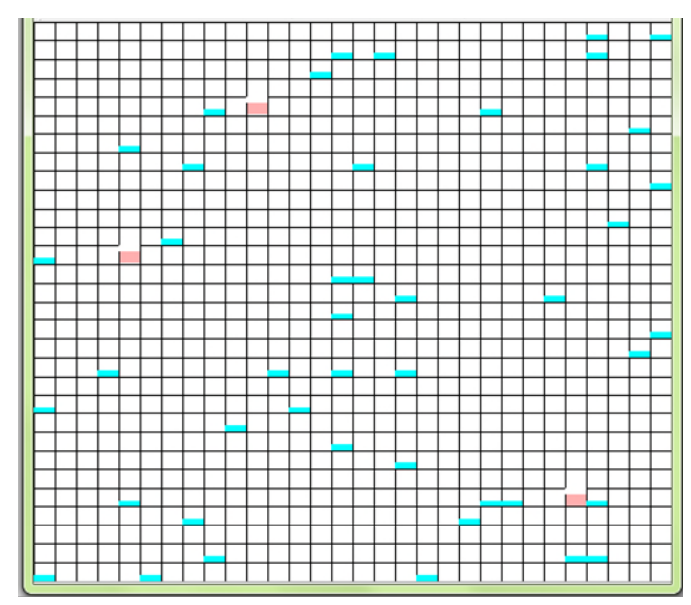

b. The start control of PICCS spatial evolution

Fig. 1 The PICCS spatial evolution simulation program.

According to the PICCS spatial evolution model, the evolving regulation of PICCS is simulated under some specific scenarios. The initial distribution of the model is shown in Fig. 3. Initial conditions is $M * N=30 * 30$. The number of port is 3 . The number of industry is 75. $l_{i}=\left\{l_{1}, l_{2}, \cdots, l_{8}\right\}, t_{i}=0.7$. The initial value of $q_{i}$ is random value in $[1$, 100]. $\quad q_{\operatorname{maxi}}=\{100,200,300,400,500,600,700,800\} \quad, \quad \kappa=1 \quad, \quad a=0.5 \quad, \quad b=0.5$, $c_{l}=\{10,20,30,40,50,60,70,80\}, c_{l}=\{20,40,60,80,100,120,140,160\}$. The initial price of $p_{i}$ is random value in $[1,10] . \alpha=0.3, \beta=0.5, \chi=0.2$. In PICCS spatial evolution simulation, the state of the 5th, 10th, 20th, 40th, 70th and 100th cycles is shown in Fig. 2:

From the above, we can know that port is the core area of port-industry-city. The area near the port is the area of resource gathering. All industries have a clear trend towards port. In the initial stage of PICCS development, the probability of port upgrading or reconstruction is larger than the probability of developing new port. At the same time, the priority of port upgrading or reconstruction is also able to attract more industries. There is endogenous dynamic of accumulation between ports, between port and industry, and between industries. Cluster development among different subjects can gain more benefits. 


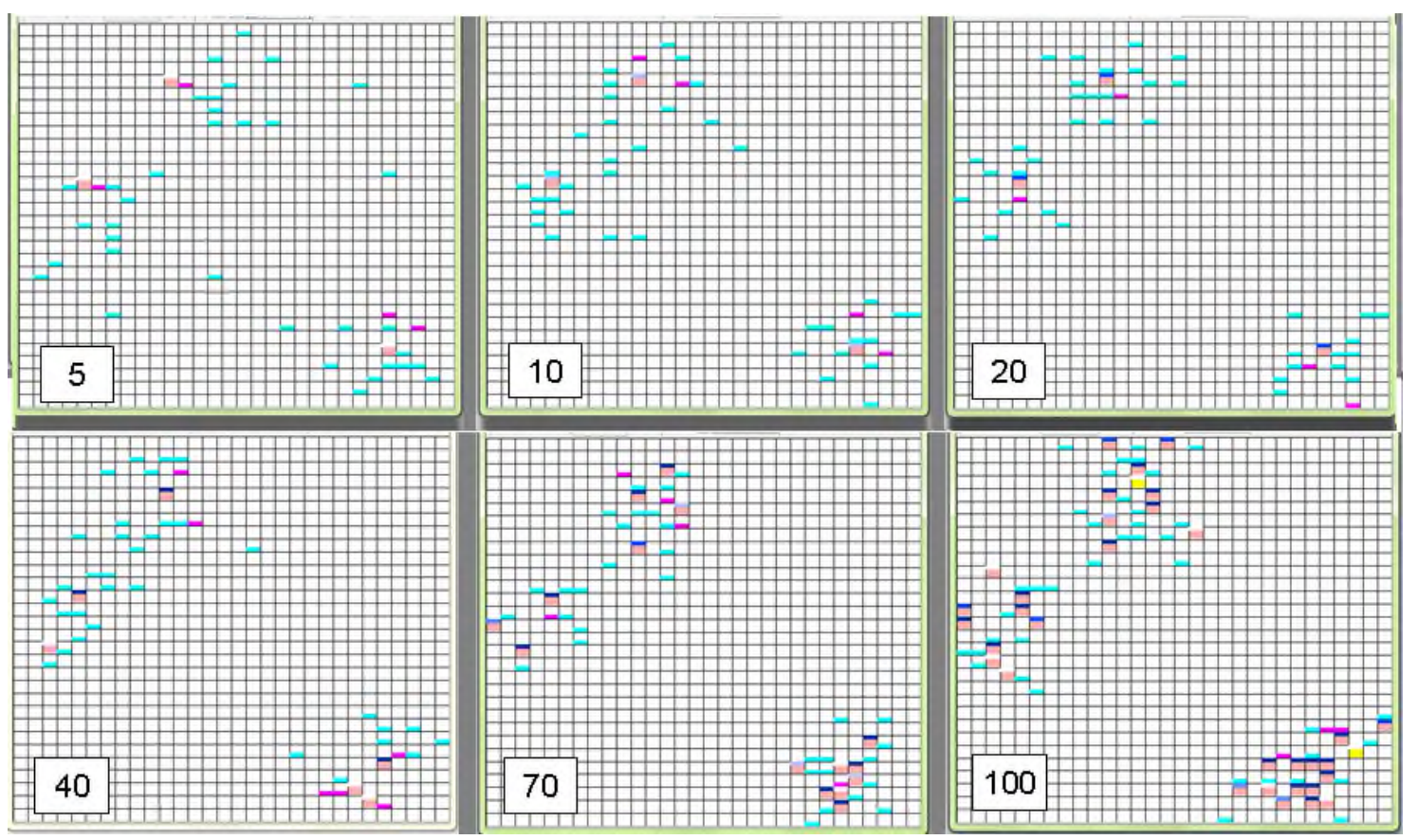

Fig. 2 The PICCS spatial evolution state of the 5th, 10th, 20th, 40th, 70th and 100th cycles.

\section{Conclusion}

This paper is based on the idea of complex adaptive system. It analyzes the mechanism and process of PICCS spatial evolution through analyzing the interactive relationship between port Agent and industry Agent in PICCS. It carries on visual simulation to the process of PICCS spatial evolution, and gets the regulation of PICCS spatial evolution. It demonstrates the feasibility and accuracy of the model. Analyzing and demonstrating the key elements in the model, distinguishing and extracting the key factors that influence PICCS spatial evolution become a further research direction.

\section{Acknowledgement}

In this paper, the research was sponsored by the National Natural Science Fund (Project No. 41401120) and the Fundamental Research Funds for the Central Universities (Project No. 2014B00214).

\section{References}

[1] R. J. McCalla. From St. John's to Miami: Containerization at the eastern seaboard ports. Geo. J. 48(1) (1999) 21-28.

[2] E. C. Stephanie. Disasters and transport systems: loss, recovery and competition at the Port of Kobe after the 1995 earthquake. J. Transport Geogr. 8(1) (2000) 53-65.

[3] J. W. James, B. Slack, The evolution of a region al container port system: The Pearl River Delta. J. Transport. Geogr. 8(4) (2000) 263-275.

[4] D. W. Song. Port co-opetition in concept and practice. Maritime Policy Manage. 30(1) (2003) $29-44$.

[5] T. Notteboom, J. P. Rodrigue, Port regionalization: Towards a new phase in port development. Maritime Policy Manage. 32(3) (2005) 297-313.

[6] X. J. Feng, L. P. Jiang, Y. Zhang, W. Wang. Optimization of Capacity of Ports Within a Regional Port System. Transport. R. Record. 2222 (2011) 10-16. 
[7] H. Chen, W. X. Luan, Y. W. Wang, Research on the function model of port city in China. Region. R. Dev. 31(2) (2012) 54-58.

[8] Z. Q. Gao, D. H. Chang, W. H. Ye. The analysis of port city's evolution trend and the choice of sustainable development strategy. Chinese Popul. Resour. Environ. 20(5) (2012) 102-109.

[9] L. P. Jiang, X. J. Feng, W. Wang. Coordination degree model of port-industry-city complex system. Water Conservancy Econ. 29(1) (2011) 11-14.

[10]Z. L. Zi. Research on the development of Dalian Port's industry cluster. Master Thesis Dalian Maritime U. 2012

[11]S. Yang, J. Pan. Dynamic simulation and control strategy of port-city coupling development—Take Lian Yun Gang as an example. Geogr. R. 30 (6) (2011) 1021- 1031. 